\title{
Correction to: Measuring and understanding adherence in a home- based exercise intervention during chemotherapy for early breast cancer
}

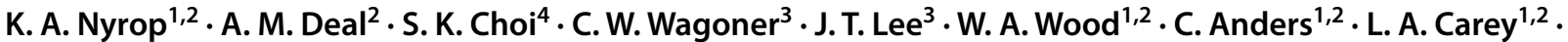 \\ E. C. Dees ${ }^{1,2} \cdot$ T. A. Jolly ${ }^{1,2} \cdot$ K. E. Reeder-Hayes ${ }^{1,2} \cdot$ H. B. Muss ${ }^{1,2}$
}

Published online: 11 October 2018

๑) Springer Science+Business Media, LLC, part of Springer Nature 2018

\section{Correction to: Breast Cancer Res Treat (2018) 168:43-55 https://doi.org/10.1007/s10549-017-4565-1}

In the original publication, the sixth author name was published incorrectly as A. Wood. The correct author name should read as W. A. Wood.

The original article can be found online at https://doi.org/10.1007/ s10549-017-4565-1.

\section{K. A. Nyrop}

kirsten_nyrop@med.unc.edu

1 Division of Hematology/Oncology, School of Medicine, University of North Carolina at Chapel Hill, 170 Manning Drive, Campus, PO Box 7305, Chapel Hill, NC 27599-7305, USA

2 Lineberger Comprehensive Cancer Center, University of North Carolina at Chapel Hill, Chapel Hill, NC, USA

3 Department of Exercise and Sport Science, University of North Carolina at Chapel Hill, Chapel Hill, NC, USA

4 Department of Health Behavior, Gillings School of Global Public Health, University of North Carolina at Chapel Hill, Chapel Hill, NC, USA 